\title{
Protée
}

\section{Histoires discrètes (quelques fêlures) de Carol Dallaire}

Le spectre et l'illusion

\section{Jean-Pierre Vidal}

Volume 35, numéro 3, hiver 2007

Poétiques de l'archive

URI : https://id.erudit.org/iderudit/017479ar

DOI : https://doi.org/10.7202/017479ar

Aller au sommaire du numéro

Éditeur(s)

Département des arts et lettres - Université du Québec à Chicoutimi

ISSN

0300-3523 (imprimé)

1708-2307 (numérique)

Découvrir la revue

Citer cet article

Vidal, J.-P. (2007). Histoires discrètes (quelques fêlures) de Carol Dallaire : le spectre et l'illusion. Protée, 35(3), 51-60. https://doi.org/10.7202/017479ar d'utilisation que vous pouvez consulter en ligne.

https://apropos.erudit.org/fr/usagers/politique-dutilisation/ 


\title{
HISTOIRES DISCRÈTES (quelques fêlures) DE CAROL DALLAIRE
}

\author{
Le spectre et l'illusion
}

Dans I'amnésie hébétée qui nous tient désormais lieu de civilisation, quelques allumés des arts et de la technoscience chantent avec enthousiasme l'abandon tranquille de l'espèce humaine vouée à une disparition bientôt joyeusement consentie pour cause séculaire d'insuffisance. Un surhomme fort peu nietzschéen pointe son nez cybernétique et prétend faire de sa mémoire un simple outil de multiplication. Les gourous transhumains et posthumains occupent le marché; ils confisquent l'avenir, comme s'ils l'avaient déjà couché, poussière de quotidien, dans leur journal intime.

C'est au contraire dans l'incertitude de l'espace mémoriel que Carol Dallaire inscrit ses superpositions et ses filigranes, ses brusques apparitions et ses lents effacements, comme autant d'étapes d'une profondeur de champ qui dit l'imbécile inutilité de tous ces rêves d'un devenir golem de l'humanité. Car la mémoire ne se contrôle pas, elle s'imagine tout au plus. C'est ainsi que toute mémoire est toujours plus vaste et plus diffuse que la conscience individuelle qui prétend la renfermer.

On connaît l'anecdote: en 1796, le jeune Henri Beyle, en passe de devenir Stendhal, franchit les Alpes avec l'armée de Bonaparte partie pour la gloire italienne et bientôt l'empire. Racontant la chose plus tard, il dit se souvenir parfaitement de ce cheval qu'il a vu chuter, entraînant son cavalier dans un précipice. Puis il se reprend: cette image, elle ne lui appartient pas, c'est plutôt, avoue-t-il, un détail d'un tableau célèbre de Gros exaltant le futur Napoléon. Dans cette illusion qui sans doute nous berce tous - ce détail, là, dans l'image historique, c'est moi; je suis là, invisible mais reconnaissable, à côté du grand homme: j'ai vu ce qu'il a vu - se marque bien plus que la mémoire fabulée que savent maintenant reconnaître les psychologues contemporains: c'est tout le texte humain, irrémédiablement tissé d'autre et d'ailleurs, qui déroule sa tapisserie ajourée.

Les I.L. et E.L. de Dallaire promènent leurs constatations souvent perplexes dans un univers de traces où le quotidien se conjugue à la célébrité littéraire, où l'image se décline et se pille, où d'infimes événements se font épingler comme des insectes de l'histoire. Rébus eux-mêmes, puisque leur signifiant est aussi, par ce point qui le troue, une paire d'initiales ouvrant, comme une ligne de fuite, sur une mystérieuse et incertaine identité, il et elle, tour à tour ou ensemble, égrènent l'anamorphose du voir en relançant notre regard. Ils ont l'étoffe dont, comme disait Shakespeare, sont faits les rêves.

Ils arborent l'ironique et insolente présence des graffiti partout où une surface s'offre à leur archive. Et en signant implicitement d'un très joycien H.C.E., Here Comes Everybody, leur discrète intervention dans le monde, ils insistent doucement sur les contours incertains de nos identités.

Dans sa tranquille effervescence, I'œuvre de Carol Dallaire redit à l'envi que nous sommes toujours, en tout temps, criblés d'altérité. Elle se fait ainsi l'écho, à son niveau et dans son transformisme militant, du célèbre aphorisme de Jarry: «Le signe seul existe, provisoire».

Jean-Pierre Vidal 
E.L. lisait son journal an hasard des pages, pour changer, disait-elle, l'importance des faits. Quand les nouvelles devenaient trop mauvaises, E.L. découpait les textes en petits fragments qu'elle assemblait au mur en une suite de minuscules événements sans conséquence. Alors, elle souriait. 


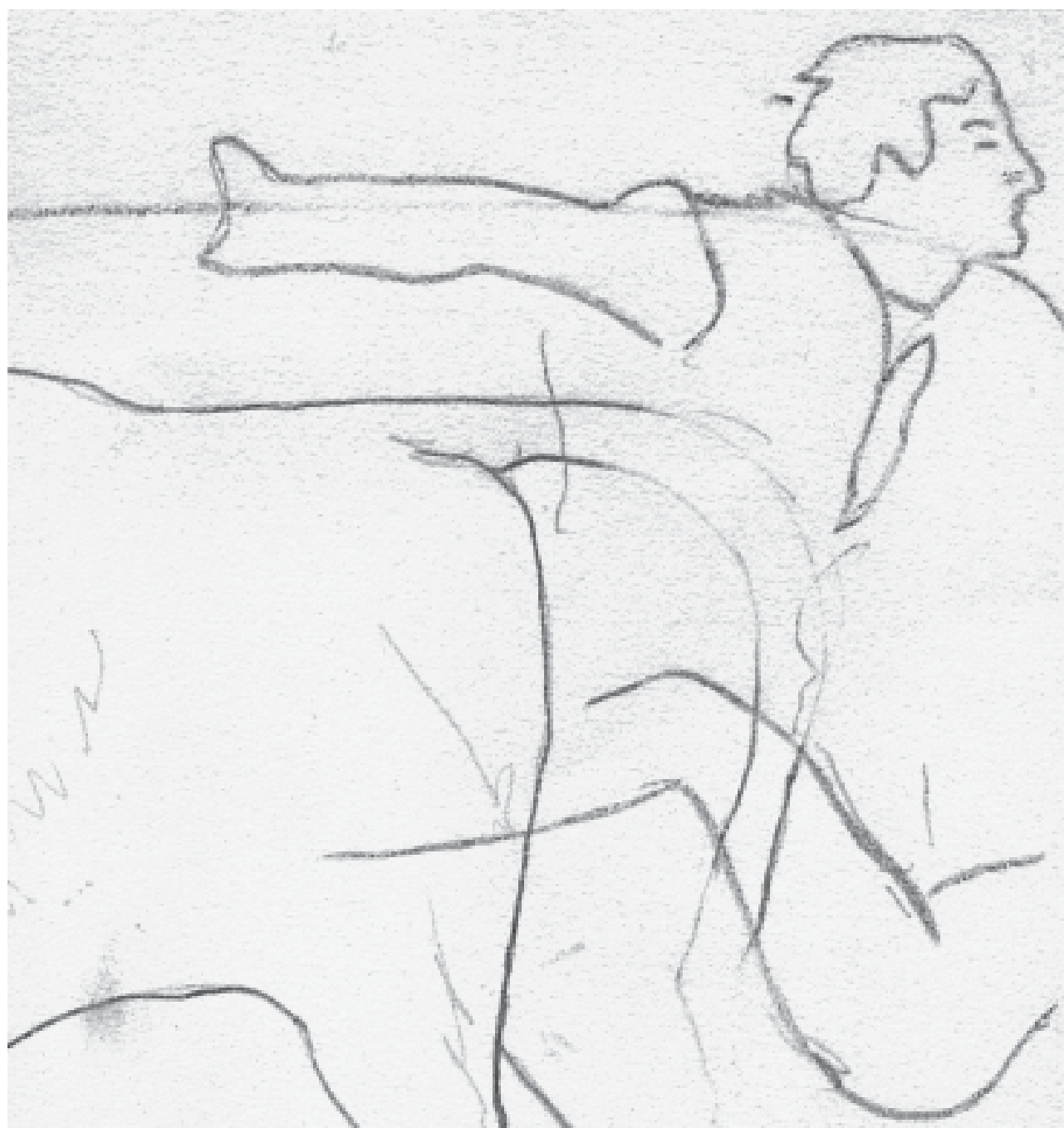

1.L. aimait dessiner des crompes et les dessinait de mémoire, disait-j. Y.L. Davait jamais en de modèles et en était fier. Qertaing amis, sans le lui dire, détestaient ces dessing quj encombraient leurs murs.

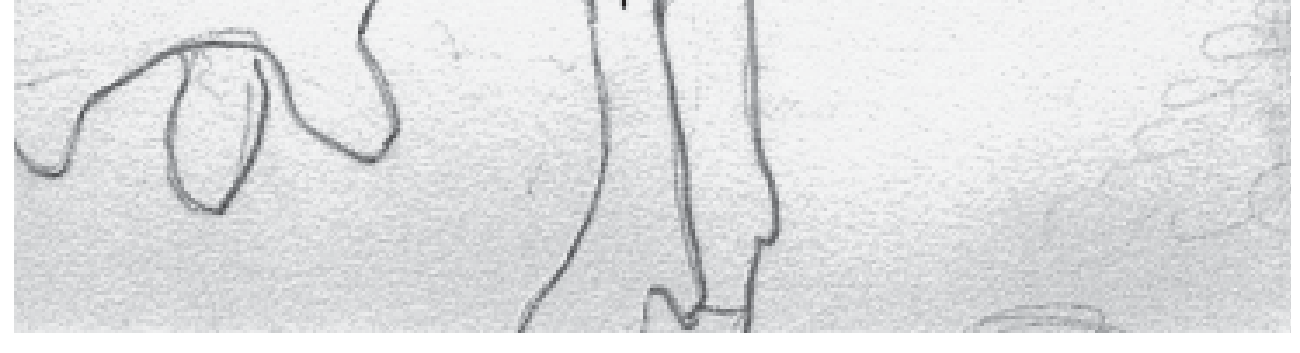

53 


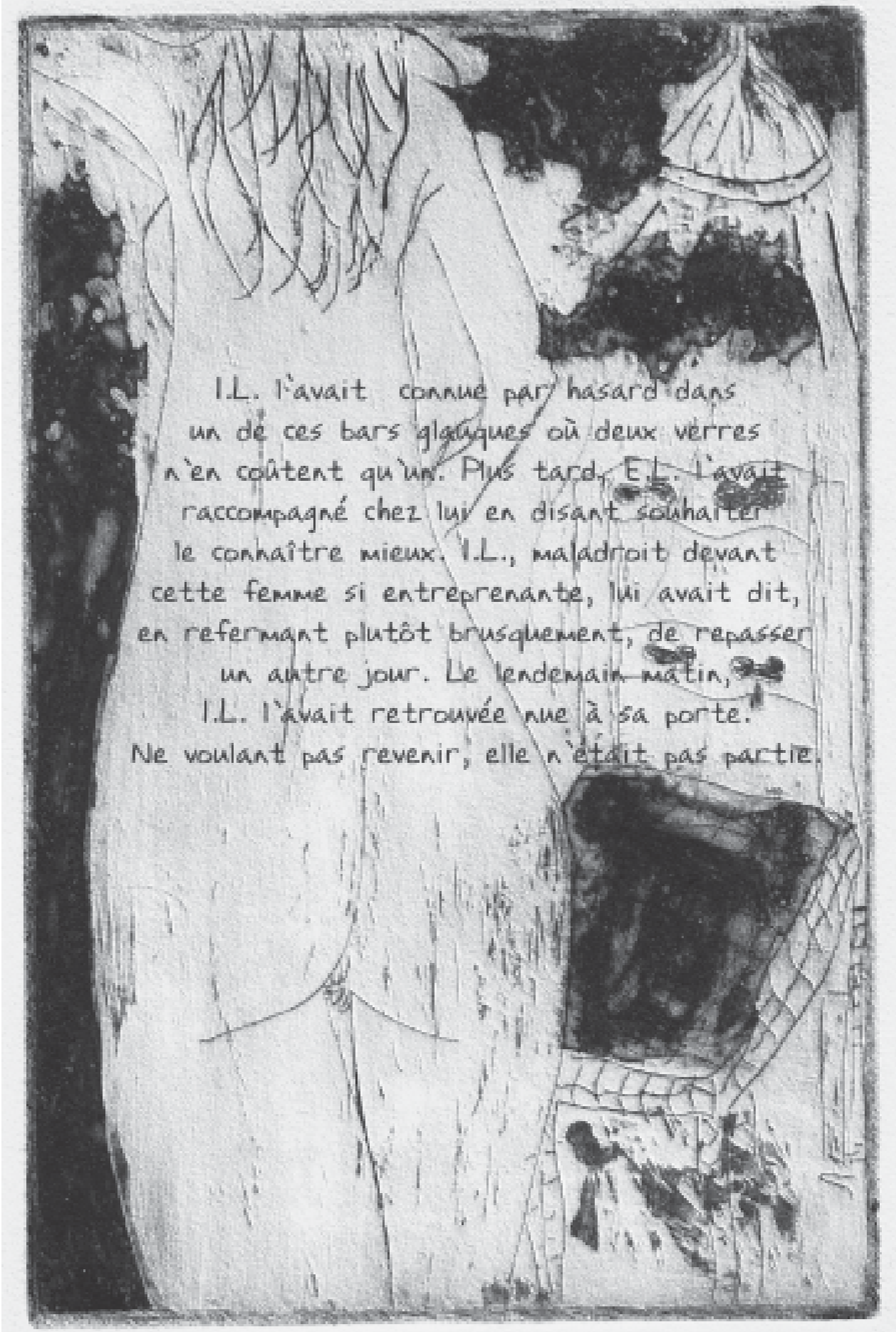




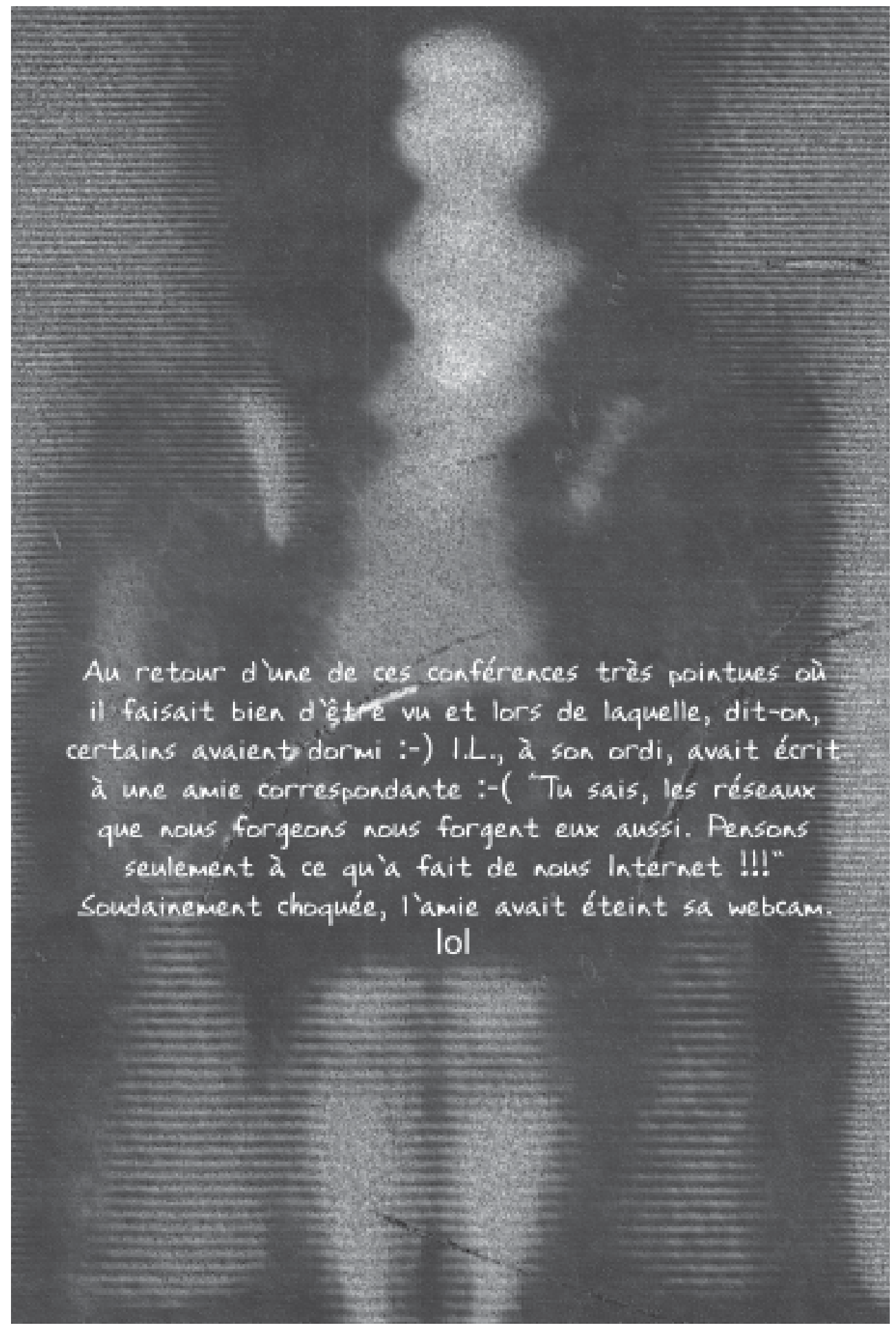




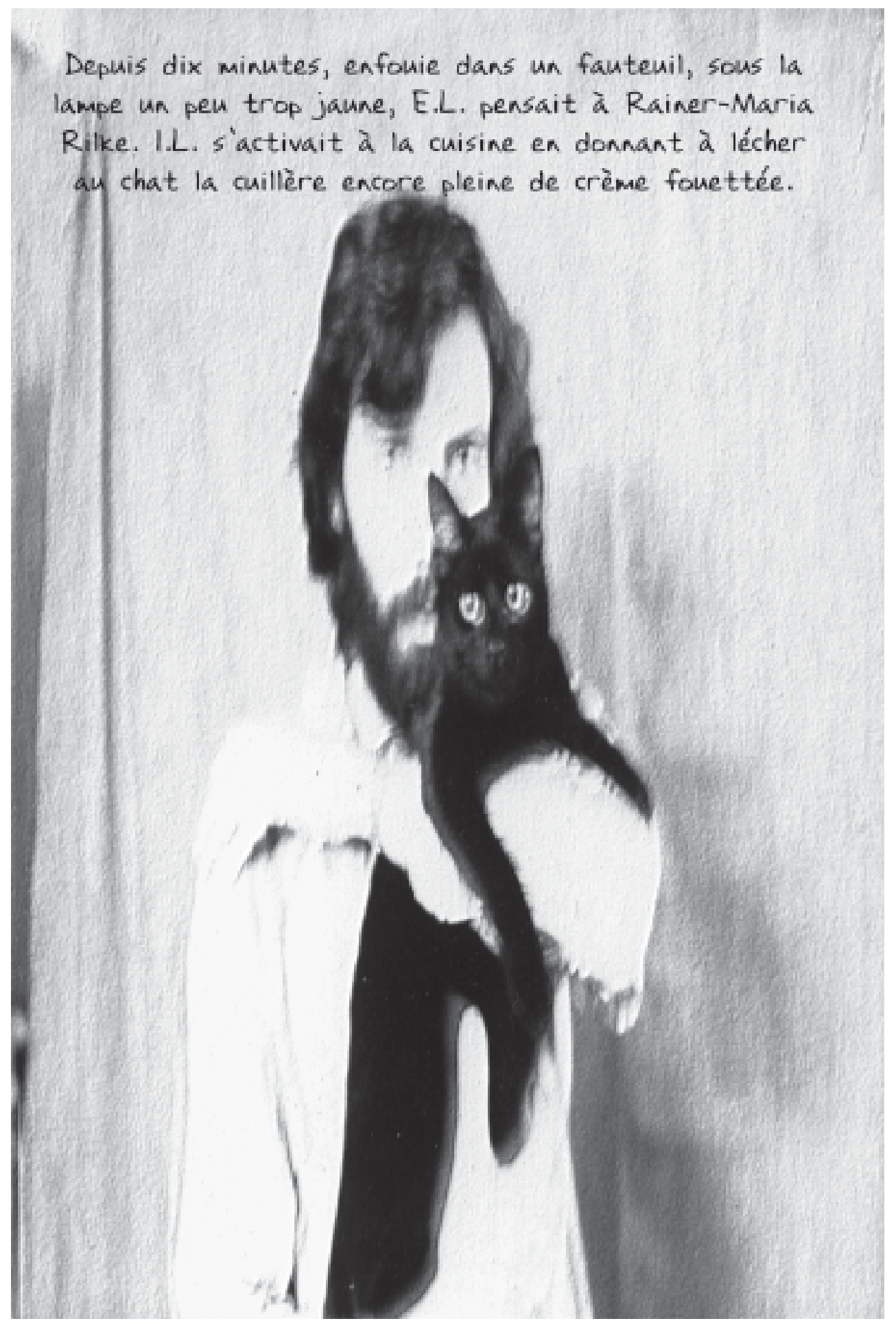




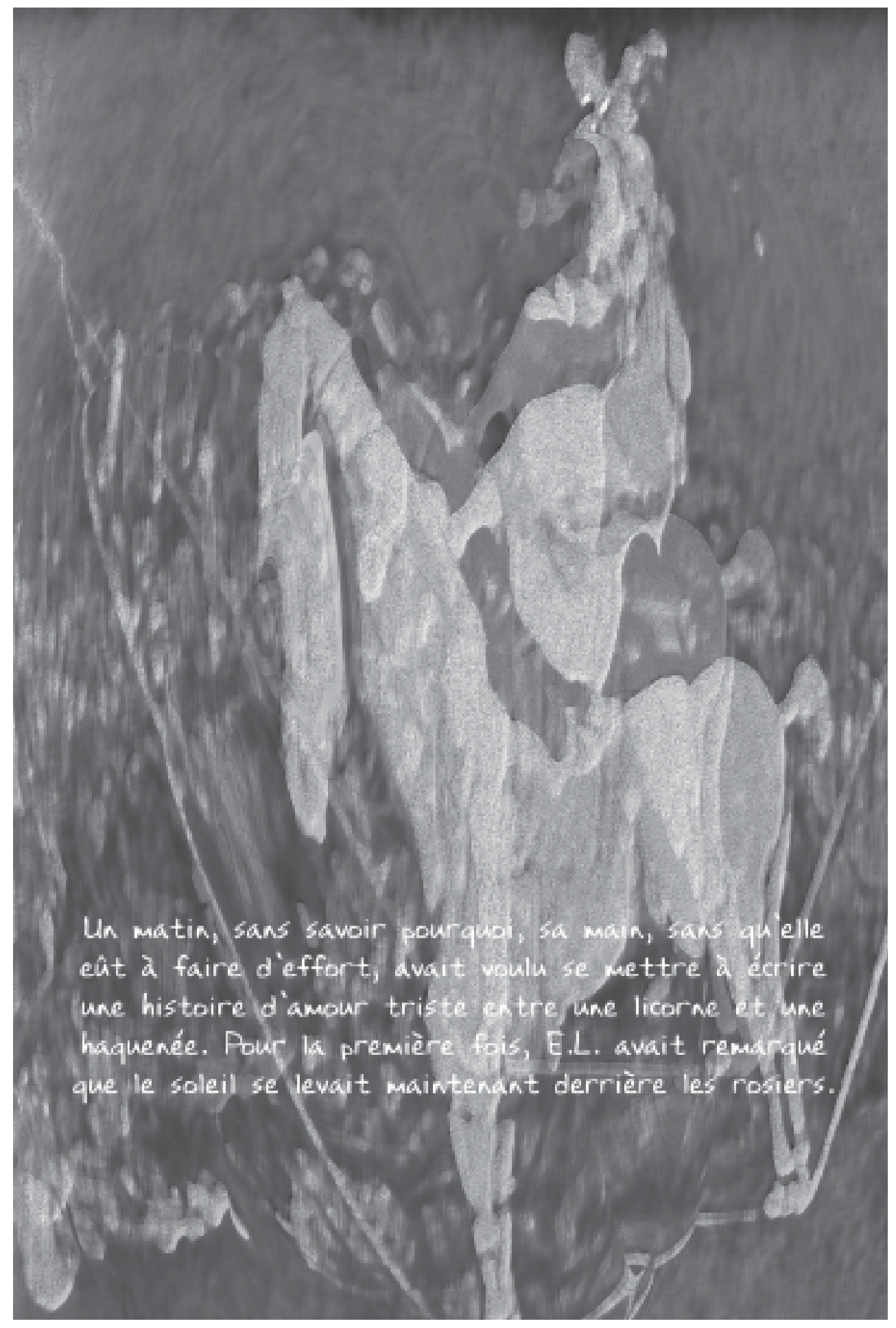









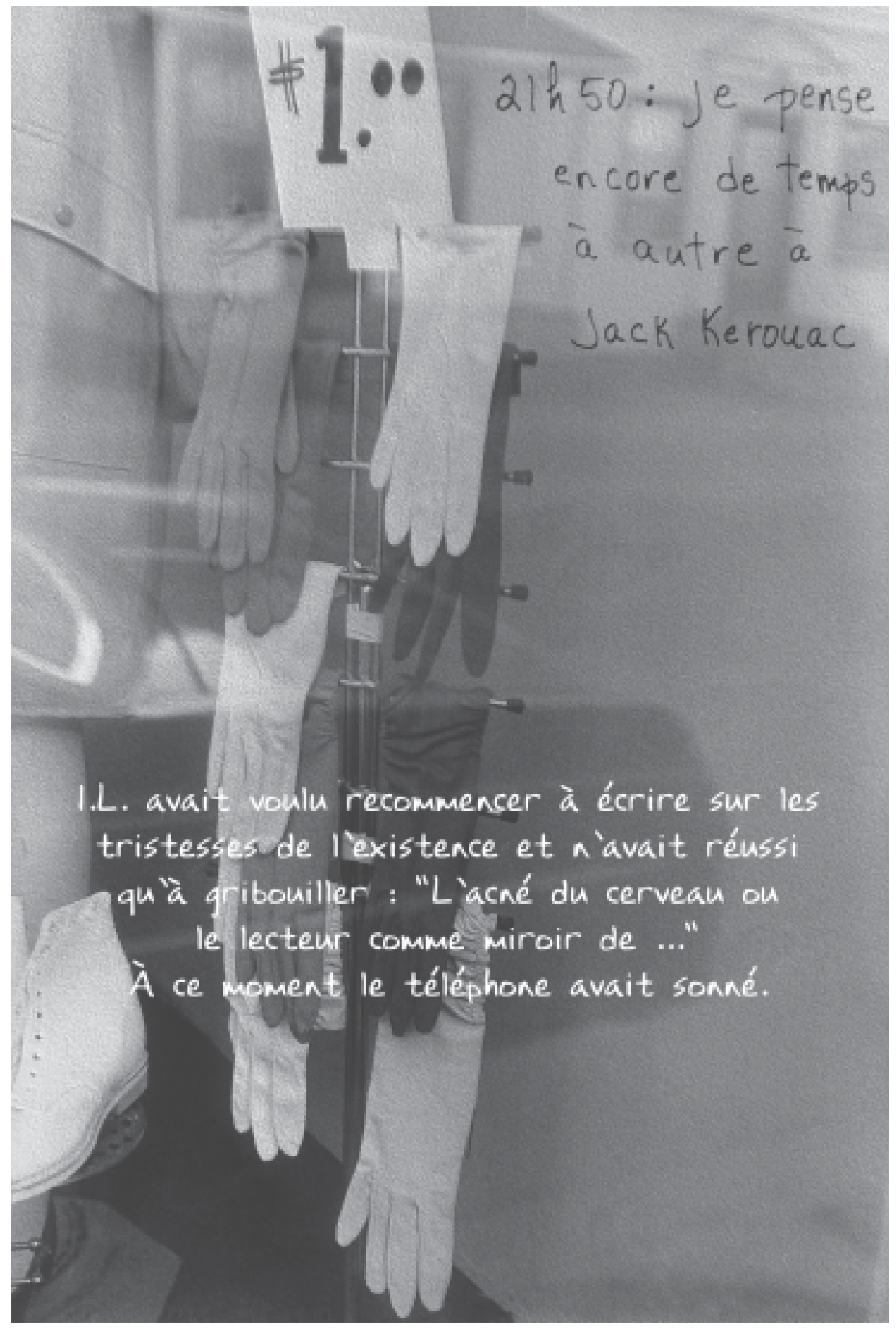


Enfant, I.L. adorait les livres d'images aux pages jaunies trop sèches ou, au contraire, malodorantes d'humidité et en voulait encore à Joyce d'avoir osé un jour écrire :

Je peux me psoakaanalyyser quand je le veux

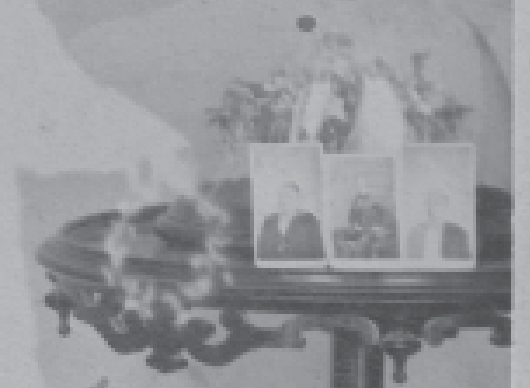

e

t 20

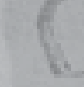

